\title{
A social work study on relationship between leadership style and organization change: A case study of Semnan high schools' teachers
}

\author{
Mohammad Reza Iravani $^{\mathbf{a}^{*}}$, Seyed Esmael Mosavi ${ }^{\mathrm{b}}$, Amin Movahedi', Gholamali Iravani $^{\mathrm{d}}$, \\ Akbar Iravani ${ }^{\mathrm{e}}$
}

${ }^{a}$ Department of Social Work, Islamic Azad University of Khomeinishahr, Khomeinishahr Branch, Daneshjou Blvd, Iran

${ }^{b}$ Counseling department, Islamic Azad University of Khomeinishahr, Khomeinishahr Branch, Daneshjou Blvd, Iran

${ }^{c}$ Master of Social Work

${ }^{d}$ Applied and Technical University

${ }^{e}$ PameNoor University, Iran \& Secretary of Education, District 4, Esfahan, Iran

A R T I L E I N F O AB S T A C T

Article history:

Received April 202012

Received in Revised form

June 282012

Accepted 29 July 2012

Available online

August 32012

Keywords:

Leadership style

Organizational change

Consideration

Initiating structure

\begin{abstract}
The primary objective of this survey is to study the relationship between leadership style among teachers who work in high schools and their orientation on organizational change. The study is performed among students who attended guided schools in province of Semnan, Iran. There are five hypotheses associated with the proposed study of this paper including managers' attitudes on change based on demographic characteristics, the relationship between leadership style and organizational change, the effects of different leadership styles and the organizational change orientation in terms of demographical characteristics. Statistical population includes all teachers who for high schools in city of Semnan, Iran and the study used a sample of 373 people who were randomly selected from three regions of the city. The proposed study used standard leadership questionnaire based on initiating structure and consideration originally developed at Ohio university in two dimensions with 30 questions. The questionnaire also used another type questionnaire consists of 32 questions with three dimensions of structure, technology and employee. The results indicate that there is no meaningful relationship between leadership style and gender, leadership style and job experience, organizational change and gender, management change and gender.
\end{abstract}

\section{Introduction}

Leadership style plays important role on educational systems and it could help learning facilitates and improve the quality of teaching. There are literally different studies on learning the relationship between leadership style and management changes. Oğuz (2010) studied the relationship between the leadership style of the school administrators and the organizational citizenship behaviors of teachers. The study explains that the concept of organizational citizenship is not teachers' task definitions, they are the actions performed with free will, and they can increase teachers' job satisfaction and

* Corresponding author. Tel.: + 989130758065

E-mail addresses: iravani@iaukhsh.ac.ir (M. R. Iravani) 
productivity in their working environment. The style of leadership of school administrators has a substantial impact on the gaining process of organizational citizenship for teachers. Oğuz (2010) performed a study using 204 volunteer primary school teachers who worked in Samsun city center and the data were collected by looking into the "Organizational Citizenship Behaviors Scale" and "The Leadership Style Questionnaire". According to the findings, the participants had positive tendencies about the organizational citizenship behaviors in the schools they work in. However, participants' opinions have had a substantial diversity in terms of gender, branch, education level and variable seniority. There was also a meaningful and positive relationship between the organizational behaviors of teachers and transactional and transformational leadership styles of school administrators.

Testa (2009) investigated the relationship between cultural congruence, perceived leadership style, leader-member exchange (LMX) and employee citizenship behaviors. The results suggested that cultural similarity influenced employee perceptions of LMX relations and organization citizenship behaviors, but not leadership style. Zembat et al. (2010) performed an investigation to analyze the relationship between the effectiveness of preschools and their managers' leadership styles, based on teachers' opinions and managers from the preschool year of elementary schools and from independent kindergartens among some teachers who were randomly chosen from the city of Istanbul, Turkey. According to their results, there was a parallel relationship between the effectiveness of schools and high leadership skills possessed by managers.

Bosu et al. (2011) performed an investigation on notions of leadership agency and 'social justice' within an African educational context, with a specific focus on the school level. The study presented some positive influences generated by the headteachers' actions and indicated ways in which these actions illustrated developments in areas of 'social justice' associated with fairness, equity, recognition, and redistribution. The findings suggest that empowering headteachers through the use of action research could enable them to act creatively and positively to benefit the quality of education offered to the pupils within their schools. Byrne and Bradley (2007) investigated the effects of culture on leadership efficiency by studying on how personal and national cultures could influence leadership style. They studied the differences of the two perspectives of cultures on effective leadership. Benjamin and Flynn (2006) considered the relationship between regulatory orientation and transformational leadership and investigated whether the effectiveness of transformational leadership depends on followers' regulatory mode. They reported that regulatory mode was measured as a chronic disposition and the other in which it was situationally induced.

Lope Pihie et al. (2011) performed an investigation on Malaysian higher education institutions and specifically Research Universities (RUs). They reported that administrators' leadership styles had influenced on lecturers' job satisfaction and played essential role in materialization of research university's goals and vision. Currie et al. (2009) investigated the leadership and institutional change in the public sector on a case study of secondary schools in England. They examined the co-existence of an emerging, results-oriented, government-prescribed approach to leadership (the new institution) with a more traditional professional value-based approach (the old institution). Their results suggested that there were no significant performance differences between the two leadership approaches and school context did not appear to impact the leadership style employed. The analysis also suggested that although the new regulatory environment had fostered the development of the results-oriented leadership, it had not fully replaced professional value-based leadership. They reported that pockets of resistance to the policy-prescribed approach exactly in those areas, which were targeted by the policy, namely, in schools with high percentage of socially deprived students. They concluded that a complex relationship exists between leadership and its institutional context.

Mattar (2012) investigated different factors influencing the performance of public schools in Lebanon. They reported that factors influencing school performance include students' SES and their quality, teachers' quality (their ability and the quality of work life) and the way they were motivated, 
the principal's leadership style, and the schools' physical working conditions. Lo et al. (2010) examined the impact of transformational leadership style on employees' organizational commitment to change in Malaysia higher education context. Their findings suggested that two dimensions of transformational leadership style namely, idealized influence and inspirational motivation had positive relationship with personal commitment to change.

In this paper, we study the relationship between leadership style among teachers who work in high schools and their orientation on organizational change.

\section{The proposed study}

The study was performed among students who attended guided schools in province of Semnan, Iran. There are five hypotheses associated with the proposed study of this paper including managers' attitudes on change based on demographic characteristics, the relationship between leadership style and organizational change, the effects of different leadership styles and the organizational change orientation in terms of demographical characteristics. Statistical population includes all teachers who for high schools in city of Semnan, Iran and the study used a sample of 373 people who were randomly selected from three regions of the city. The proposed study used standard leadership questionnaire based on initiating structure and consideration originally developed at Ohio university in two dimensions with 30 questions. The questionnaire also used another type questionnaire consists of 32 questions with three dimensions of structure, technology and employee. The study used different statistical observations including t-student, multi-variable regression analysis, analysis of variance and the results were analyzed.

\subsection{Research hypotheses}

There are five hypotheses associated with the proposed study of this paper, which are as follows,

1.There is a relationship between the management team's willingness on organizational changes and educational characteristics including school and education types and educational specialty.

2.There is a relationship between leadership style and type of school, management educational background and their work experiences.

3.There is a relationship between leadership educational style (initiating structure and consideration) and their tendency to make organizational change.

4.There is a relationship between managements' leadership style and their tendencies on making organizational changes based on type of schools and managers' educational background.

5.There is a relationship between managements' gender and management change.

\subsection{Demographical characteristics}

In our study, 41 managers participated in our survey and 17 people representing 40.74 percents could only finish a two-year college while the remaining 24 people representing $59.26 \%$ maintained a bachelor degree of science. In addition, 23 managers were enrolled in boys' high school and the remaining 18 managers were managing girls' high schools. Among 366 students who participated in our survey, 119(43.9\%) were female and the remaining 247(56.3\%) were male. Cronbach alpha was calculated as 0.94 , which is well above the minimum acceptable limit.

\section{The results}

In this section, we present details of our survey on five hypotheses. 


\subsection{Leadership style and gender}

The first hypothesis is associated with relationship between the leadership style and gender. Table 1 shows details of our results.

\section{Table 1}

Statistical results between leadership style and gender

\begin{tabular}{|c|c|c|c|c|}
\hline \multicolumn{5}{|c|}{ Average ranking } \\
\hline Leadership style & male & female & $\mathrm{Z}$ & P-Value \\
\hline Initiating structure & 12.23 & 16.21 & 1.29 & 0.195 \\
\hline Consideration & 11.87 & 16.67 & 1.561 & 0.118 \\
\hline
\end{tabular}

As we can observe from the results of Table 1, there is no meaningful relationship between leadership style and gender when the level of significance is five percent.

\subsection{Leadership style and education}

The second hypothesis is associated with relationship between the leadership style and gender. Table 2 shows details of our results.

Table 2

Statistical results between leadership style and educational background

\begin{tabular}{|c|c|c|c|c|}
\hline \multicolumn{4}{|c|}{ Average ranking } & \multirow[b]{2}{*}{ P-Value } \\
\hline Leadership style & 2-year college & Bachelor degree & $\mathrm{Z}$ & \\
\hline Initiating structure & 16.79 & 11 & 1.89 & 0.058 \\
\hline Consideration & 17.96 & 9.73 & 2.69 & 0.0071 \\
\hline
\end{tabular}

According to the results of Table 2, there is a meaningful relationship between leadership style and educational background in one case. In other words, those managers who completed two-year colleague degree consider management changes more than the other group of people do.

\subsection{Leadership style and years of educational background}

The second hypothesis is associated with relationship between the leadership style and gender. Table 3 shows details of our results.

\section{Table 3}

Statistical results between leadership style and work experiences

\begin{tabular}{lcccc}
\hline \multicolumn{7}{c}{ Average ranking } & & \\
\hline Leadership style & Less than 2 years & Five and more & P-Value \\
\hline Initiating structure & 13.32 & 15.93 & 0.747 & 0.455 \\
Consideration & 13.25 & 16.14 & 0.830 & 0.406 \\
\hline
\end{tabular}

As we can observe from the results of Table 3, there is no meaningful relationship between leadership style and years of job experience when the level of significance is five percent.

\subsection{Organizational change and gender}

The fourth hypothesis is associated with relationship between the organizational change and gender.

\section{Table 4}

Statistical results between organizational change and gender

\begin{tabular}{lcccc}
\hline & \multicolumn{2}{c}{ Average ranking } & Z & P-Value \\
\hline Management change & male & female & 1.31 & 0.187 \\
\hline Change in technology & 12.20 & 16.25 & 1.70 & 0.087 \\
Change in employee & 11.67 & 16.69 & 1.41 & 0.157 \\
Change in structure & 12.07 & 16.64 & \\
\hline
\end{tabular}


As we can observe from the results of Table 4, there is no meaningful relationship between organizational change and gender when the level of significance is five percent.

\subsection{Organizational change and gender}

One other hypothesis is associated with relationship between the organizational change and gender.

\section{Table 5}

Statistical results between organizational change and gender

\begin{tabular}{lcccc}
\hline & \multicolumn{3}{c}{ Average ranking } & \\
\hline Management change & male & female & Z & P-Value \\
\hline Change in technology & 12.20 & 16.25 & 1.31 & 0.187 \\
Change in employee & 11.67 & 16.69 & 1.70 & 0.087 \\
Change in structure & 12.07 & 16.64 & 1.41 & 0.157 \\
\hline
\end{tabular}

As we can observe from the results of Table 4, there is no meaningful relationship between management change and gender when the level of significance is five percent.

\subsection{Organizational change and educational background}

Another hypothesis is associated with relationship between the organizational change and educational background. Table 6 shows details of our results.

\section{Table 6}

Statistical results between organizational change and educational background

\begin{tabular}{lcccc}
\hline \multicolumn{2}{c}{ Average ranking } & & \\
\hline Management change & 2-year college & Bachelor degree & $\mathrm{Z}$ & P-Value \\
\hline Change in technology & 16.00 & 11.85 & 1.35 & 0.174 \\
Change in employee & 15.75 & 12.12 & 1.189 & 0.234 \\
Change in structure & 16.04 & 11.81 & 1.38 & 0.166 \\
\hline
\end{tabular}

As we can observe from the results of Table 6, there is no meaningful relationship between organizational change and educational background when the level of significance is five percent.

\subsection{Organizational change and educational background specialties}

The other hypothesis is associated with relationship between the organizational change and educational background specialties in terms of management skills and other types of educational backgrounds. Table 7 shows details of our results.

\section{Table 7}

Statistical results between organizational change and educational management skills

\begin{tabular}{|c|c|c|c|c|}
\hline \multicolumn{5}{|c|}{ Average ranking } \\
\hline Management change & Management & Others & $\mathrm{Z}$ & P-Value \\
\hline Change in technology & 11.50 & 14.88 & 0.968 & 0.332 \\
\hline Change in employee & 10.86 & 15.10 & 1.217 & 0.223 \\
\hline Change in structure & 11.57 & 14.85 & 0.940 & 0.346 \\
\hline
\end{tabular}

As we can observe from the results of Table 7, there is no meaningful relationship between organizational change and types of educational background (management or other skills) when the level of significance is five percent.

\subsection{Pearson correlation test}

In this section, we investigate the relationship between initiating structure and consideration in one side and change in technology, employee and structure on the other side. Table 8 shows the results along with P-value between each pair of comparison. 
Table 8

Pearson correlation test results between leadership style and management change

\begin{tabular}{lcccc}
\hline Leadership style & Change in technology & Change in employee & Change in structure & Making change \\
\hline Initiating structure & 0.709 & 0.7614 & 0.7327 & 0.8000 \\
P-value & 0.000 & 0.0000 & 0.0000 & 0.0000 \\
\hline Consideration & 0.783 & 0.8111 & 0.7612 & 0.8300 \\
P-value & 0.000 & 0.0000 & 0.0000 & 0.0000 \\
\hline
\end{tabular}

As we can observe from the results of Table 8, there are positive correlations between leadership style, initiating structure and consideration, with management change in most cases and all of them are meaningful when the level of significance is one percent.

\section{Conclusion}

In this study, we have investigated the relationship between leadership style among teachers who worked in high schools and their orientation on organizational change. The study was performed among students who attended guided schools in province of Semnan, Iran. Based on the results of the survey we have found that there was no meaningful relationship between leadership style and gender. However, there was a meaningful relationship between leadership style and educational background in one case. In other words, those managers who completed two-year colleague degree considered management changes more than the other group of people did. There was no meaningful relationship between leadership style and job experience, no meaningful relationship between organizational change and gender, no meaningful relationship between management change and gender. Finally, we have found no meaningful relationship between organizational change and educational background and no meaningful relationship between organizational change and types of educational background.

\section{References}

Benjamin, L., \& Flynn, F.J. (2006). Leadership style and regulatory mode: Value from fit? Organizational Behavior and Human Decision Processes, 100(2), 216-230.

Bosu, R., Dare, A., Dachi, H., \& Fertig, M. (2011). School leadership and social justice: Evidence from Ghana and Tanzania. International Journal of Educational Development, 31(1), 67-77.

Byrne, G.J., \& Bradley, F. (2007). Culture's influence on leadership efficiency: How personal and national cultures affect leadership style. Journal of Business Research, 60(2), 168-175.

Currie, G., Lockett, A., \& Suhomlinova, O. (2009). Leadership and institutional change in the public sector: The case of secondary schools in England. The Leadership Quarterly, 20(5), 664-679.

Lo, M.C., Ramayah, T., \& de Run, E.C. (2010). Does transformational leadership style foster commitment to change? The case of higher education in Malaysia. Procedia - Social and Behavioral Sciences, 2(2), 5384-5388.

Lope Pihie, Z.A., Sadeghi, A., \& Elias, H. (2011). Analysis of head of departments leadership styles: Implication for improving research university management practices. Procedia - Social and Behavioral Sciences, 29, 1081-1090.

Mattar, D.M. (2012). Factors affecting the performance of public schools in Lebanon. International Journal of Educational Development, 32(2), 252-263.

Ogguz, E. (2010). The relationship between the leadership styles of the school administrators and the organizational citizenship behaviours of teachers. Procedia - Social and Behavioral Sciences, 9, 1188-1193.

Testa, M.R. (2009). National culture, leadership and citizenship: Implications for cross-cultural management. International Journal of Hospitality Management, 28(1), 78-85.

Zembat, R., Koçyiğit, S., Tuğluk, M.N., \& Doğan, H. (2010). The relationship between the effectiveness of preschools and leadership styles of school managers. Procedia - Social and Behavioral Sciences, 2(2), 2269-2276. 